\title{
STUDI KASUS PENGARUH EFISIENSI SUPPLY CHAIN TERHADAP KINERJA PENGELOLAAN UANG TUNAI (Studi pada Divisi Sentra Layanan Perbankan Elektronik PT Bank Central Asia TBK)
}

\author{
Anna Susilowati \\ Program Studi Magister Manajemen Universitas Tarumanagara \\ annakartiko@gmail.com
}

Masuk : 25-11-2019, revisi : 21-12-2019 diterima untuk diterbitkan : 23-12-2019

\begin{abstract}
Cash at PT Bank Central Asia no longer faced logistics issues but has turned into a matter of optimizing the cash management costs of the cash balance managed. The managed balance should consider the needs of customers in branches and ATMs. Therefore, researchers feel the need to establish the amount of cash needed to be available in the branch and to make an estimate of the amount of money to be prepared Not idle. The money that is idle can be a conference for other purposes that generate income from the interest rate. The target in this study is to achieve a target of cash management costs amounting to $0.2 \%$ of the cash balance managed. Analysis process to find the root of the problem has not achieved the target cost of management of cash is by using PDCA method (Plan, Do, Check, Action), Fishbone diagram and Pareto diagram. The result of the calculation of the ideal balance and the forecasting of the ATM replenishing the performance, which is very significant cost efficiency so that the target set can be achieved.
\end{abstract}

Keywords : Cash Optimation Management, Supply Chain Management, Cash ATM Replenish

Abstrak : Uang tunai di PT Bank Central Asia tidak lagi menghadapi masalah logistik namun telah beralih menjadi masalah optimalisasi biaya pengelolaan uang tunai terhadap saldo uang tunai yang di kelola. Saldo yang dikelola harus mempertimbangkan kebutuhan nasabah di cabang maupun di ATM. Untuk itu peneliti merasa perlu untuk menetapkan jumlah kebutuhan uang tunai yang harus tersedia di cabang serta melakukan perkiraan jumlah uang yang harus dipersiapkan agar tidak idle. Uang yang idle tersebut dapat dikonversikan untuk keperluan lain yang menghasilkan pendapatan dari interest rate. Target pada penelitian ini adalah mencapai target biaya pengelolaan uang tunai sebesar $0.2 \%$ dari saldo uang tunai yang dikelola. Proses analisa untuk menemukan akar masalah pada belum tercapainya target biaya pengelolaan uang tunai yaitu dengan menggunalan metode PDCA (Plan, Do, Check, Action), fishbone diagram dan diagram pareto. Hasil dari adanya perhitungan saldo ideal dan peramalan pengisian ATM ini memperoleh peningkatan kinerja yaitu efisiensi biaya yang sangat signifikan sehingga target yang ditetapkan dapat tercapai.

Keywords : Optimalisasi Manajemen Kas, Supply Chain manajemen, Pengisian uang ATM

\section{PENDAHULUAN}

Saldo uang tunai di PT Bank Central Asia, TBK (Bank BCA) terdiri dari saldo kas operasional dan saldo kas ATM. Pada tahun 2014 rata- rata per bulan saldo kas Cash Processing Center Jakarta ada pada posisi Rp 19.741 Miliar sedangkan pada tahun 2017 Rp 31.109 Miliar terdapat kenaikan sebesar 37\%. Biaya pengelolaan uang tunai yang timbul di tahun 2015 sebesar Rp 122 Miliar dan pada tahun 2017 sebesar Rp 89 Miliar atau turun sebesar 27\%. Sedangkan ratio biaya terhadap saldo pada tahun 2015 sebesar 0.62 dan di tahun 2017 menjadi 0.36 . 
Pengelolaan uang tunai ini harus mampu menyelesaikan masalah sebagai berikut :

1. Meminimalkan biaya pengelolaan uang tunai

2. Menjadi bagian dalam meningkatkan profit

3. Melakukan improvement untuk meningkatkan kepuasan nasabah

Biaya pengelolaan uang tunai belum dapat memenuhi target yang ditetapkan oleh manajemen yaitu sebesar $0.2 \%$ dari saldo yang dikelola. Saldo uang tunai yang dikelola adalah persediaan uang tunai untuk operasional cabang dan persediaan pengisian ATM. Penelitian ini bertujuan untuk mencari akar masalah serta memperdalam pencarian solusi agar target dapat tercapai.

\section{LANDASAN TEORI}

Studi perintis dalam literatur fisik optimasi tunai adalah oleh Baumol (1952) dan Tobin (1958), secara independen mengembangkan model ekonomi dari permintaan transaksi uang. Dengan mengasumsikan bahwa arus masuk kas dan arus keluar stabil dan dapat diprediksi, para peneliti menerapkan model kuantitas pesanan ekonomi untuk membangun keseimbangan target kas. Dalam model para peneliti, trade-off antara cash holding and interest-bearing assets didefinisikan untuk menentukan tingkat optimal ketersediaan kas.

Para peneliti mempertimbangkan tiga biaya utama: the cost of cash, the cost of cash uploading and the cost of daily services. Ekinci, Lu, \& Duman (2015) mengintegrasikan hasil perkiraan dengan model optimasi pengisian kas untuk menentukan jumlah uang dan jadwal logistik yang diperlukan untuk pengisian uang tunai di semua ATM. Agoston, Benedek, \& Gilanyi (2016) mendefinisikan masalah manajemen kas sebagai masalah tunggal dengan memasukkan masalah optimasi uang tunai bank ke dalam masalah optimasi uang perusahaan CIT. Untuk mengurangi biaya manajemen kas keseluruhan, termasuk biaya transportasi dan biaya bunga, para peneliti mendefinisikan model optimalisasi bersama dengan menggunakan harga kontrak antara bank dan perusahaan CIT.

Sebagian besar makalah tentang optimalisasi manajemen kas berusaha untuk mengoptimalkan uang tunai dalam jaringan ATM. Namun, manajemen tingkat kas di cabang dan pengiriman uang tunai antara lokasi pusat dan cabang juga memainkan peran penting dalam pengelolaan kas dari lembaga keuangan. Namun demikian, kajian pustaka kami mengungkapkan bahwa hanya ada dua kajian yang meliputi pengoptimalan kas cabang: (Lazaro, Jimenez, \& Takeda, 2018), (Osorio \& Toro, 2012).

Supply Chain Management adalah sistem yang mengintegrasikan proses bisnis utama yang dimulai dari konsumen hingga ke pemasok untuk memberi nilai tambah bagi konsumen maupun stakeholders (standard Global SCM Forum).

\section{METODE PENELITIAN}

PDCA, merupakan singkatan dari Plan, Do, Check dan Act adalah suatu proses pemecahan masalah, empat langkah iteratif yang umum digunakan dalam pengendalian kualitas. Metode ini dipopulerkan oleh W. Edwards Deming, yang sering dianggap sebagai bapak pengendalian kualitas modern sehingga sering juga disebut dengan siklus Deming.

\section{ANALISA PENYEBAB MASALAH}

Permasalahan pada BCA yaitu biaya pengelolaan uang tunai yang belum dapat mencapai target disebabkan oleh :

a. Biaya atas saldo idle di cabang dan di cash center menyebabkan biaya pengelolaan uang tunai belum mencapai target sebesar $0,2 \%$ dari saldo kas yang dikelola.

b. Supply chain yang tidak efisien, menggunakan perusahaan yang berbeda beda untuk proses uang dan pengisian ATM, sehingga waktu tunggu 2-3 hari sampai uang tunai dapat dimanfaatkan oleh nasabah. 
c. Persediaan uang di cabang, cash center dan ATM tidak akurat berdasarkan kebutuhan tarikan atau setoran nasabah.

\section{SOLUSI}

Solusi yang tepat yaitu End to End Process yang merupakan suatu terobosan baru yang dilakukan oleh BCA dengan melakukan pemetaan ulang jumlah uang masuk dengan jumlah uang keluar serta memotong proses non value added untuk meminimalkan uang idle yang tidak menguntungkan dalam pengelolaan uang tunai.

\section{Saldo Kas Operasional}

Agar ada panduan bagi cabang dalam mengelola saldo harus ditentukan suatu acuan berdasarkan kebutuhan nasabah yang disebut dengn cash flow ratio, yaitu ratio untuk mengukur efisiensi dari saldo uang tunai di cabang. CFR ini dihitung untuk data transaksi selama satu bulan.

Rumus dasar dari CFR adalah sebagai berikut :

$\mathrm{CFR}=$ (rata rata saldo uang tunai) $/$ (rata rata net mutasi)

Rata rata net mutasi :

1. Cabang plus : rata rata net mutasi positif

2. Cabang minus : rata rata net mutasi negative

3. Cabang fluktuatif : rata rata net mutasi diperhitungkan secara seimbang antara net mutasi negative dan net mutasi positif.

Cara perhitungan saldo ideal :

Cara menghitung rata rata saldo ideal sebuah cabang adalah sebagai berikut :

a. Saldo $(\mathrm{CFR})$ ideal $=($ CFR ideal $\mathrm{x}$ rata rata saldo kas operasional $) / \mathrm{CFR}$ riil

b. Saldo $(\mathrm{ATM})$ ideal $=$ rata rata pengisian ATM per hari $\mathrm{x}$ koefisien pengisian

c. Saldo (support $\mathrm{KCP}$ ) ideal $=1 \mathrm{x}$ rata rata net mutasi positif dari $\mathrm{KCP}$

\section{Standarisasi pengisian ATM dengan melakukan sentralisasi order pengisian ATM}

Dibawah ini digambarkan flow process sebelum penerapan end to end process dan setelah penerapan solusi end to end process :

Sebelum End to End Process :

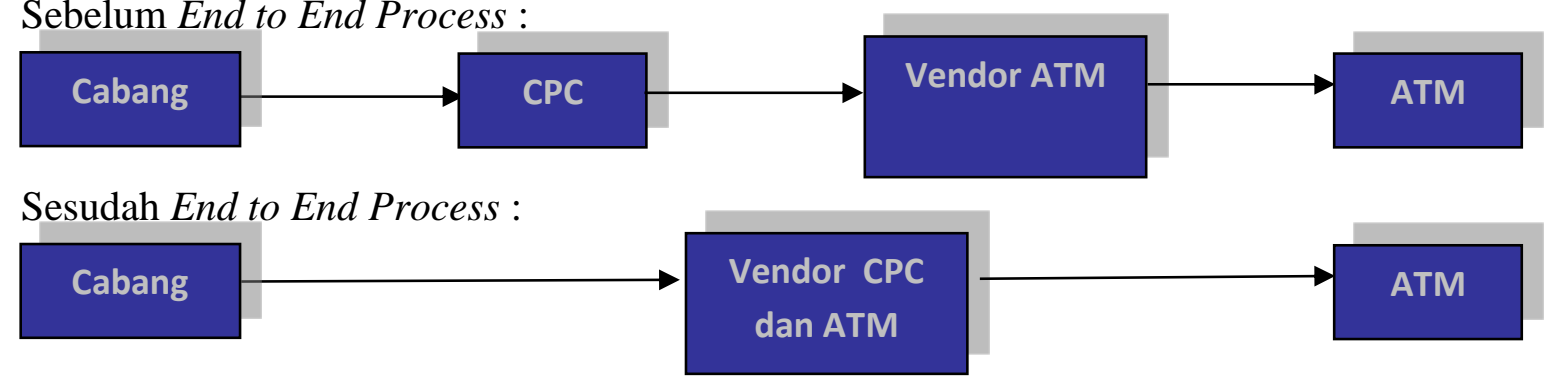

\section{KESIMPULAN}

Project End to End Process terbukti berhasil memberikan manfaat yang berarti bagi PT BCA,Tbk dalam pengelolaan kas yang lebih optimal.

1. Biaya

Biaya pengelolaan uang tunai operasional tercapai 0.15 atau sebesar IDR 49 Miliar Target project tercapai di tahun pertama implementasi (2018) penghematan total sebesar Rp 40 Miliar.

2. Supply Chain

Menurunkan $87.5 \%$ delivery trip pengiriman uang antar CPC dari 4.608 trip di tahun 2017 menjadi 576 trip di tahun 2018. Tahun pertama implementasi menurunkan $87.5 \%$ 
delivery trip pengiriman uang antar CPC dari 4.608 trip di tahun 2017 menjadi 576 trip di tahun 2018.

3. Kualitas
a. Frekuensi kasus uang habis sebanyak 11.902 di tahun 2018 sehingga turun sebesar $70 \%$.
b. Pengisian ATM menjadi 11.78 kali rata-rata per bulan per mesin ATM.
c. Uang tunai sisa lokasi tercapai sebesar $28 \%$.

\section{DAFTAR PUSTAKA}

Anderson, Dean \& Anderson, L.A. (2010). Beyond Change Management. Pfeifer, San Fransisco.

Bass, B.M, Avolio, B.J. \& Goodheim, L. (1987). Biography and the assessment of transformational leadership at the world class level. Journal of Management,13:7-19.

Boon, O.K., \& Arugumam, V. (2006). The influence of corporate culture on organizational commitment: Case study of semiconductor organization in Malaysia. Sunway Academic Journal, 3, 99-155.

Conger, J.A., Kanungo, R.N., Menon, S.T. 2000. "Charismatic Leadership and Follower Effects.", Journal of Organizational Behavior, No. 21, pg 747-767.

Denison, D.R. (2000). Organizational culture: Can it be a key lever for driving organizational change. In S. Cartwright, \& C. Cooper (Eds), the handbook of organizational culture (pp. 347-372). John Wiley \& Sons, London.

Denison, D.R., \& Mishra, A.K. (1995). Toward a theory of organizational culture effectiveness. Organization Science, 6(2), 204-223.

Fleishman, A dan Peters, D.R. (1962). Leadership Attitudes and Managerial "Success", Personel Psychology. 127-143.

Gibson James. L, Ivancevich John M dan Donnely James H, Jr. (1996). Organisasi: Perilaku, Struktur dan Proses. Terjemahan. Jilid 1. Penerbit Binarupa Aksara, Jakarta.

Hofstede, G., Bram, N., Denise, D.O. and Geert, S. (1990). Measuring Organizational Culture: A Qualitative and Quantitative Study across Twenty Cases. Administrative Science Quarterly. (35) : 286-316

Kasali, R. (2018). The Great Shifting. Gramedia, Jakarta.

Kotter, J.P., Heskett, J.L. (2011). Corporate culture and performance. New York: Free Press.

Ling, B. Guo, Y, Chen, Chen, D. (2000). "Change Leadership and Employee's Commitment to Change.”, Journal of Personal Psychology, Vol. 17 No.2, pg 83-93.

Luthans, Fred. (2002). Organizational Behavior. ninth Edition. McGraw-Hill. Inc., New York. Meyer, J.P., \& Herscovitc, L. (2001). Commitment in the workplace: Toward a general model. Human Resource Management Review, 11(3), 299-326.

Nikpour, A. (2016). "The Impact of Organizational Culture on Organizational Performance: The Mediating Role of Employee's Organizational Commitment.”, International Journal of Organizational Leadership No 6, pg 65 -72.

Organ, D.W. (1998). Organizational citizenship behavior: The good soldier syndrome. Lexington, MA: D.C. Heath.

Podsakoff, P.M., MacKenzie, S.B., Bommer, W.H. (1996). "Transformational Leader Behaviors and Substitutes for Leadership as Determinants of Employee Satisfaction, Commitment, Trust, and Organizational Citizenship Behaviors.", Journal of Management, Vol. 22 No. 2, pg 259-298.

Shokory, S.M., Suradi, N.R.M. (2018). "Transformational Leadership and Its Impact on Extra Role Performance of Project Team Members : The Mediating Role Work Engagement.”, Academy of Strategy Management Journal, Vol. 5 No. 5.

YukI, G. (1999). An Evaluative Essay on Current Conception of Effective Leadership. European Journal of Work and Organizational Psychology, 8(1), 33-48. 